\section{(6) OPEN ACCESS}

\title{
Non-invasive neuromodulation for migraine and cluster headache: a systematic review of clinical trials
}

\author{
Uwe Reuter, ${ }_{1}^{0}$ Candace McClure, $^{2}$ Eric Liebler, ${ }_{1}^{3}$ Patricia Pozo-Rosich ${ }^{4,5}$
}

\begin{abstract}
- Additional material is published online only. To view please visit the journal online (http://dx.doi.org/10.1136/ jnnp-2018-320113).

${ }^{1}$ Department of Neurology, Charité-Universitätsmedizin Berlin, Berlin, Germany ${ }^{2}$ North American Science Associates, Minneapolis, Minnesota, USA

${ }^{3}$ electroCore, Inc, Basking Ridge, New Jersey, USA

${ }^{4}$ Headache and Craniofacial Pain Unit, Neurology Department, Hospital Universitari Vall d'Hebron, Barcelona, Spain ${ }^{5}$ Headache Research Group, VHIR, Universitat Autònoma de Barcelona, Barcelona, Spain
\end{abstract}

Correspondence to Dr Uwe Reuter, Department of Neurology, CharitéUniversitätsmedizin Berlin, Berlin 10117, Germany; uwe. reuter@charite.de

Received 30 November 2018 Revised 21 January 2019 Accepted 22 January 2019 Published Online First 1 March 2019

Check for updates

(C) Author(s) (or their employer(s)) 2019. Re-use permitted under CC BY-NC. No commercial re-use. See rights and permissions. Published by BMJ.

To cite: Reuter U, McClure C, Liebler E, et al. J Neurol Neurosurg Psychiatry 2019:90:796-804.

\section{ABSTRACT}

Non-invasive neuromodulation therapies for migraine and cluster headache are a practical and safe alternative to pharmacologics. Comparisons of these therapies are difficult because of the heterogeneity in study designs. In this systematic review of clinical trials, the scientific rigour and clinical relevance of the available data were assessed to inform clinical decisions about non-invasive neuromodulation. PubMed, Cochrane Library and ClinicalTrials.gov databases and the WHO's International Clinical Trials Registry Platform were searched for relevant clinical studies of non-invasive neuromodulation devices for migraine and cluster headache (1 January 1990 to 31 January 2018), and 71 were identified. This analysis compared study designs using recommendations of the International Headache Society for pharmacological clinical trials, the only available guidelines for migraine and cluster headache. Non-invasive vagus nerve stimulation (nVNS), singletranscranial magnetic stimulation and external trigeminal nerve stimulation (all with regulatory clearance) were well studied compared with the other devices, for which studies frequently lacked proper blinding, sham controls and sufficient population sizes. nVNS studies demonstrated the most consistent adherence to available guidelines. Studies of all neuromodulation devices should strive to achieve the same high level of scientific rigour to allow for proper comparison across devices. Devicespecific guidelines for migraine and cluster headache will be soon available, but adherence to current guidelines for pharmacological trials will remain a key consideration for investigators and clinicians.

\section{INTRODUCTION}

Non-invasive neuromodulation alters neural activity through the stimulation of nerves or neural tissue. This technology is emerging as a practical and safe alternative to conventional pharmacological interventions for the treatment of migraine and cluster headache. ${ }^{1}$ The demonstrated efficacy and safety of several non-invasive neuromodulation therapies, including non-invasive vagus nerve stimulation (nVNS), external trigeminal nerve stimulation (e-TNS) and single-pulse transcranial magnetic stimulation (sTMS), has generated interest among clinicians and patients. ${ }^{23}$ The clearance of these therapies by CE mark in the European Union and the US Food and Drug Administration (FDA) provides an alternative for the treatment of primary headache. ${ }^{4-6}$ These devices could present a unique flexible treatment option because they can be used as an early therapy, either independently or concomitantly with pharmacological treatment. Non-invasive neuromodulation also offers a novel alternative for those in sensitive patient populations (eg, pregnant women or adolescents), or for those affected by poor tolerability or lack of efficacy with pharmacologics.

Comparisons among the expanding number of non-invasive neuromodulation device trials are challenging because of the heterogeneity of clinical study designs and range of predefined efficacy outcomes. These inconsistencies among the non-invasive neuromodulation trials may be due in part to the absence of guidelines for conducting trials in primary headache. While such guidelines are in development, clinicians should currently base their treatment decisions on the best available evidence from rigorous clinical trials. Until non-invasive neuromodulation-specific study recommendations become available, neuromodulation trials designed and conducted in accordance with existing guidelines of the International Headache Society (IHS) for controlled studies of pharmacological therapies continue to provide the greatest scientific rigour and consistency. ${ }^{7}$ Adherence to future guidelines currently under development will allow for greater uniformity among studies to help clinicians make informed decisions on appropriate treatment options for their patients.

\section{Objective}

The objective of this article was to systematically review the clinical study designs of non-invasive neuromodulation trials for the treatment of migraine and cluster headache in order to assess the scientific rigour and clinical relevance of these devices and their associated clinical data. Clinicians and investigators can use this assessment to make informed decisions on treatment options and design more rigorous studies for patients with migraine and cluster headache.

\section{METHODS/LITERATURE SEARCH STRATEGY}

Four databases were systematically searched for clinical trials in the non-invasive neuromodulation of migraine and cluster headaches: PubMed. gov, the Cochrane Library, ClinicalTrials.gov and the WHO's International Clinical Trials Registry Platform (WHO-ICTRP). The Preferred Reporting Items for Systematic Reviews and Meta-Analyses (PRISMA) methodology was followed in this review.

\section{Identification of research studies}

Medline through PubMed.gov was systematically searched for all clinical trials assessing 
Table 1 Clinical trial neuromodulation devices analysis inclusion and exclusion criteria

\begin{tabular}{|c|c|}
\hline Inclusion & Exclusion \\
\hline $\begin{array}{l}\text { Non-invasive devices } \\
\text { Transcutaneous } \\
\text { Transcranial } \\
\text { External }\end{array}$ & $\begin{array}{l}\text { Invasive devices } \\
\text { Implanted } \\
\text { Percutaneous } \\
\text { Requiring surgical procedures }\end{array}$ \\
\hline $\begin{array}{l}\text { Neuromodulation device } \\
\text { Neurostimulation } \\
\text { Stimulation } \\
\text { Electrical or magnetic }\end{array}$ & $\begin{array}{l}\text { Non-peer review or registry publications } \\
\text { News articles } \\
\text { Abstracts and posters } \\
\text { Conference proceedings }\end{array}$ \\
\hline $\begin{array}{l}\text { Patients with migraine or cluster } \\
\text { headache as defined by International } \\
\text { Classification of Headache Disorders } \\
\text { Published/registered between } 1 \text { January } \\
1990 \text { and } 31 \text { January } 2018\end{array}$ & $\begin{array}{l}\text { Secondary headache-related indications } \\
\text { Traumatic brain injury } \\
\text { Cervical injury } \\
\text { Substance abuse/withdrawal } \\
\text { Non-specific or facial pain } \\
\text { Infection }\end{array}$ \\
\hline Human clinical trials only & Observational or diagnostic only \\
\hline English-language articles or registries & Review articles \\
\hline
\end{tabular}

neuromodulation treatments in migraine and cluster headache that were published between 1 January 1990 and 31 January 2018. Search terms were 'neuromodulation OR neurostimulation OR stimulation' and 'migraine OR headache'; publication type 'clinical trial NOT review'; and language 'English'. The Cochrane Library was searched for 'neuromodulation OR neurostimulation OR stimulation' in Title, Abstract, Keywords; 'migraine OR headache' in Title, Abstract, Keywords; 'NOT review' in Publication Type; and '1990' to '2018' in publication year. A search limit was placed on 'trials' only.

ClinicalTrials.gov was systematically searched for all clinical trials (ie, all types of recruitment status) assessing neuromodulation OR neurostimulation OR stimulation treatments in migraine OR headache (ie, Condition or disease) between 1 January 1990 and 31 January 2018. The WHO-ICTRP was also searched for all clinical trials (ie, all types of recruitment status) assessing neuromodulation OR neurostimulation OR stimulation (ie, Intervention) treatments in migraine OR headache (ie, Condition) between 1 January 1990 and 31 January 2018. Since the neurologic effect can be excitatory or inhibitory, the preferred term is neuromodulation rather than neurostimulation, which is used in this review. Clinical trial registration is currently required by the US FDA for approval and clearance of devices and by the International Committee of Medical Journal Editors as a condition of consideration for publication. ${ }^{9-11}$

The broad search term 'headache' was used instead of 'cluster headache' to provide comprehensive search results and minimise exclusion of relevant studies. 'Non-invasive' was not specified in the search because studies often do not explicitly categorise treatments in this manner and instead use implied terminology (eg, transcutaneous, transcranial, external).

\section{Screening}

Trials from WHO-ICTRP were cross-referenced with those from ClinicalTrials.gov, and duplicates were removed to create a master list of unique clinical trials. Research articles from PubMed and the Cochrane Library were matched to a registered

Table 2 Non-invasive neuromodulation clinical trials in acute migraine treatments

\begin{tabular}{|c|c|c|c|c|c|c|c|}
\hline \multirow[b]{2}{*}{ Device type* } & \multirow[b]{2}{*}{ Studies (n) } & \multirow{2}{*}{$\begin{array}{l}\text { Enrolled } \\
\text { population } \\
\text { (total } n \text { ) }\end{array}$} & \multirow{2}{*}{$\begin{array}{l}\text { Both aura and } \\
\text { no aura patients } \\
\text { included }(\%)\end{array}$} & \multirow{2}{*}{$\begin{array}{l}\text { Blinded } \\
\text { studies } \\
\text { (n) } \dagger\end{array}$} & \multirow{2}{*}{$\begin{array}{l}\text { Sham- } \\
\text { controlled } \\
\text { studies (n) }\end{array}$} & \multicolumn{2}{|c|}{$\begin{array}{l}\text { Percentage of studies evaluating IHS } \\
\text { recommended endpoints }\end{array}$} \\
\hline & & & & & & Primary $(\%) \ddagger$ & Secondary (\%)‡ \\
\hline \multicolumn{8}{|l|}{ Electrical nerve stimulation } \\
\hline $\begin{array}{l}\text { Non-invasive vagus nerve stimulation } \\
\text { (nVNS) }\end{array}$ & 4 & 396 & 100 & 2 & 2 & 100 & 100 \\
\hline $\begin{array}{l}\text { External trigeminal nerve stimulation } \\
\text { (e-TNS) }\end{array}$ & 3 & 196 & 100 & 1 & 1 & 33 & 100 \\
\hline $\begin{array}{l}\text { Occipital and supraorbital } \\
\text { transcutaneous nerve stimulation } \\
\text { (OS-TNS) }\end{array}$ & 3 & 106 & 100 & 2 & 3 & 0 & 100 \\
\hline $\begin{array}{l}\text { Transcranial direct current stimulation } \\
\text { (tDCS) }\end{array}$ & 1 & 32 & 100 & 0 & 0 & 0 & 0 \\
\hline $\begin{array}{l}\text { Transcranial alternating current } \\
\text { stimulation }\end{array}$ & 1 & 40 & 100 & 1 & 1 & 100 & 0 \\
\hline $\begin{array}{l}\text { Auricular transcutaneous vagus nerve } \\
\text { stimulation }\end{array}$ & 1 & 50 & 100 & 1 & 1 & 0 & 0 \\
\hline \multicolumn{8}{|l|}{ Magnetic stimulation } \\
\hline $\begin{array}{l}\text { Single-pulse transcranial magnetic } \\
\text { stimulation (sTMS) }\end{array}$ & 2 & 309 & 50 & 2 & 1 & 50 & 50 \\
\hline $\begin{array}{l}\text { Repetitive transcranial magnetic } \\
\text { stimulation (rTMS) }\end{array}$ & 1 & 201 & 0 & 1 & 1 & 100 & 100 \\
\hline \multicolumn{8}{|l|}{ Other } \\
\hline $\begin{array}{l}\text { Conditioned pain modulation } \\
\text { (CPM) }\end{array}$ & 3 & 476 & 100 & 3 & 3 & 0 & 33 \\
\hline $\begin{array}{l}\text { Intranasal kinetic oscillation } \\
\text { stimulation }\end{array}$ & 1 & 36 & 100 & 1 & 1 & 0 & 0 \\
\hline
\end{tabular}

${ }^{*}$ All references for studies in this table are listed in the online supplementary references.

tDouble-blind or better.

$\ddagger$ Percentage of efficacy studies in which either a primary or a secondary endpoint recommended by the International Headache Society was used. Safety studies were excluded from this calculation.

IHS, International Headache Society. 
clinical trial ${ }^{12}$; matched data were combined as a single record for analysis.

\section{Inclusion and exclusion criteria}

A list of a priori inclusion and exclusion criteria was applied to ensure that only relevant studies were evaluated (table 1). Only clinical trials of neuromodulation devices in patients with migraine or cluster headache, as defined by the International Classification of Headache Disorders Third Edition (or earlier editions when applicable), were eligible. ${ }^{13-15}$ Studies with patient populations that comprised comorbidities were excluded. Only trials evaluating a non-invasive treatment of the central or peripheral nervous system in migraine and cluster headache were included for analysis. Invasive neuromodulation therapies were excluded from this review because these treatments are reserved for intractable diseases and are considered separate from standard of care options. Studies that were observational or diagnostic only or that used any invasive device including acupuncture were excluded, as were studies that had only healthy patient populations or patients with non-specific pain. Only studies reported in peer-reviewed publications and/ or properly registered clinical trials were included; posters and congress abstracts were excluded from formal analysis.

Two reviewers independently reviewed the inclusion of studies according to a priori inclusion criteria. Data were independently categorised by the same reviewers and confirmed by a third reviewer. The same two reviewers evaluated the data and results of the clinical trials included in this assessment.

\section{Data collection and analysis}

The data collected in this systematic review were categorised by type of headache treatment and indication. The elements evaluated were the total patient population among all studies and whether each study was blinded, was sham controlled and used predefined IHS-recommended endpoints. For acute and preventive migraine treatments, the number of studies conforming to the IHS recommendation to include both patients with aura and without aura was also examined. ${ }^{16}$ IHS recommendations for controlled trials of drugs in migraine and cluster headache were used to evaluate whether the recommended primary and secondary endpoints were evaluated in the identified studies for each device. $^{16-18}$

All devices that are both CE marked and cleared by the FDA for migraine and cluster headache as well as devices used in more than two studies for either the acute or preventive treatment of migraine are reported in the Results section for all applicable study indications. The remaining devices that had two studies or fewer are presented only in tables 2 and 3. All devices in cluster headache were reported in the Results section.

\section{RESULTS}

\section{Search results}

Of the 647 studies identified in the systematic search, 509 were screened for eligibility, and 71 fulfilled the specified inclusion criteria (figure 1). Fifteen published studies were not registered with ClinicalTrials.gov or another WHO primary registry. Sixteen published studies had a corresponding registration and thus fulfilled the ethical recommendations for reporting results of clinical trials. ${ }^{19}$ The remaining 40 studies were registered with ClinicalTrials.gov (34 studies) or another WHO primary registry (six studies) without a corresponding publication.

The search identified non-invasive neuromodulation clinical trials in the acute treatment of migraine (20 studies), migraine prevention (48 studies), acute treatment of cluster headache (2 studies) and cluster headache prevention (2 studies). One study evaluated both acute and preventive interventions in migraine. The complete list of studies is available as online supplementary references.

Table 3 Non-invasive neuromodulation clinical trials in preventive migraine treatments

\begin{tabular}{|c|c|c|c|c|c|c|c|}
\hline \multirow[b]{2}{*}{ Device type* } & \multirow[b]{2}{*}{ Studies (n) } & \multirow{2}{*}{$\begin{array}{l}\text { Enrolled } \\
\text { population } \\
\text { (total } \mathrm{n} \text { ) }\end{array}$} & \multirow{2}{*}{$\begin{array}{l}\text { Both aura and } \\
\text { no aura patients } \\
\text { included }(\%)\end{array}$} & \multirow{2}{*}{$\begin{array}{l}\text { Blinded } \\
\text { studies } \\
\text { (n)t }\end{array}$} & \multirow{2}{*}{$\begin{array}{l}\text { Sham- } \\
\text { controlled } \\
\text { studies ( } n)\end{array}$} & \multicolumn{2}{|c|}{$\begin{array}{l}\text { Percentage of studies evaluating IHS- } \\
\text { recommended endpoints }\end{array}$} \\
\hline & & & & & & Primary $(\%) \ddagger$ & Secondary (\%)‡ \\
\hline \multicolumn{8}{|l|}{ Electrical nerve stimulation } \\
\hline Transcranial direct current stimulation (tDCS) & 18 & 855 & 94 & 15 & 15 & 50 & 72 \\
\hline Non-invasive vagus nerve stimulation (nVNS) & 4 & 626 & 100 & 3 & 3 & 100 & 33 \\
\hline External trigeminal nerve stimulation (e-TNS) & 3 & 194 & 100 & 1 & 1 & 33 & 100 \\
\hline Transcutaneous electrical nerve stimulation & 2 & 76 & 100 & 0 & 0 & 0 & 50 \\
\hline Transcutaneous supraorbital nerve stimulation & 1 & 80 & 100 & 1 & 1 & 100 & 100 \\
\hline $\begin{array}{l}\text { Auricular transcutaneous vagus nerve } \\
\text { stimulation }\end{array}$ & 1 & 58 & 100 & 1 & 1 & 0 & 100 \\
\hline Cranial electrotherapy stimulation & 1 & 68 & 100 & 1 & 1 & 100 & 100 \\
\hline \multicolumn{8}{|l|}{ Magnetic stimulation } \\
\hline $\begin{array}{l}\text { Repetitive transcranial magnetic stimulation } \\
\text { (rTMS) }\end{array}$ & 10 & 416 & 90 & 5 & 8 & 30 & 80 \\
\hline $\begin{array}{l}\text { Single-pulse transcranial magnetic stimulation } \\
\text { (sTMS) }\end{array}$ & 1 & 263 & 100 & 0 & 0 & 0 & 100 \\
\hline Deep transcranial magnetic stimulation & 1 & 14 & 100 & 0 & 0 & 0 & 100 \\
\hline \multicolumn{8}{|l|}{ Other } \\
\hline Caloric vestibular stimulation (CVS) & 3 & 291 & 67 & 2 & 2 & 100 & 67 \\
\hline Intranasal kinetic oscillation stimulation & 2 & 220 & 100 & 2 & 2 & 100 & 100 \\
\hline Auditory biofeedback & 1 & 40 & 100 & 0 & 0 & 0 & 0 \\
\hline
\end{tabular}

*All references for studies in this table are listed in the online supplementary references.

tDouble-blind or better.

$\ddagger$ Percentage of efficacy studies in which either a primary or a secondary endpoint recommended by the International Headache Society was used. Safety studies were excluded from this calculation.

IHS, International Headache Society. 


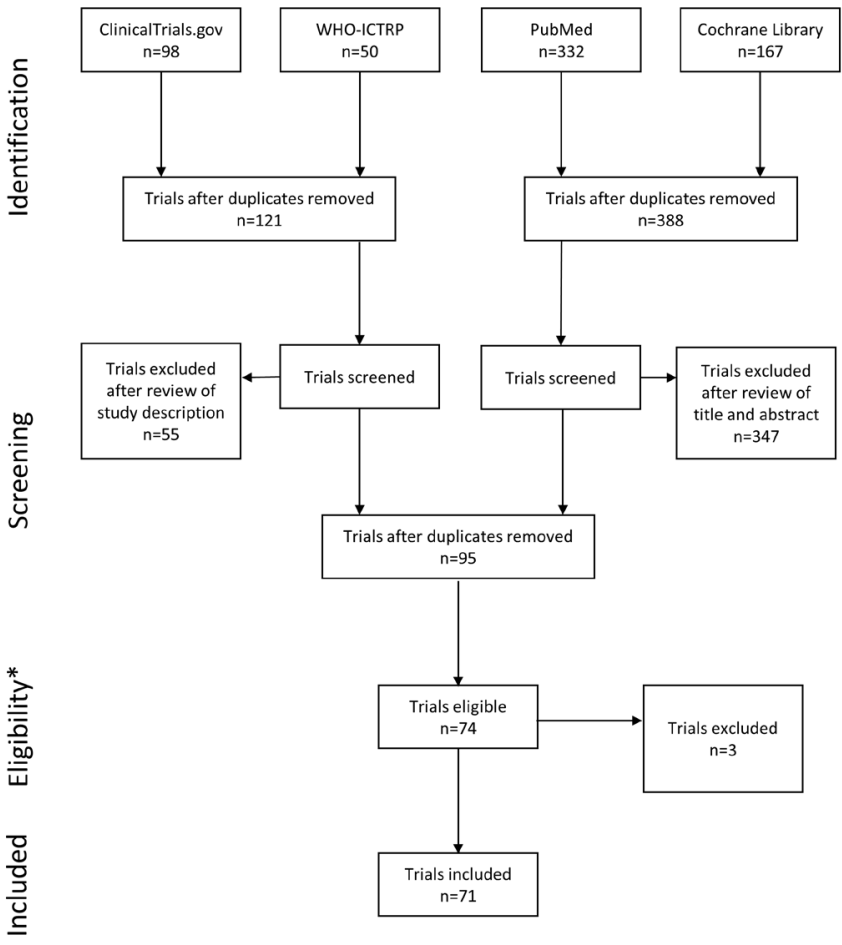

Figure 1 Flow diagram of trial selection. *Trials were excluded because study objectives were mechanistic only. ICTRP, International Clinical Trials Registry Platform. ${ }^{*}$ Trials were excluded because study objectives were mechanistic only.

This analysis compares clinical trial designs of non-invasive neuromodulation devices with the available guidelines from the IHS for acute and preventive pharmacological treatment of migraine and cluster headache. ${ }^{16-18}$ Developed as guidelines for the design of pharmacological clinical trials, the current IHS recommendations do not specifically address therapeutic devices. These guidelines were determined as the most rigorous standard against which to assess the quality of non-invasive neuromodulation studies in the treatment of migraine and cluster headache.

Devices with more than two studies for an indication are reported. Six devices each had two or fewer studies in the acute treatment of migraine (table 2), and eight devices each had two or fewer studies in migraine prevention (table 3). All devices with studies evaluating the treatment of cluster headache are presented in table 4 . The devices reported based on these criteria are as follows: nVNS, e-TNS, repetitive transcranial magnetic stimulation (rTMS), transcranial direct current stimulation (tDCS), occipital and supraorbital transcutaneous nerve stimulation (OS-TNS), conditioned pain modulation (CPM) and caloric vestibular stimulation (CVS). sTMS was evaluated in only three studies (ie, two in acute treatment; one in preventive treatment) but is included because of its CE mark and FDA clearance as both an acute and preventive treatment for migraine.

\section{Non-invasive vagus nerve stimulation}

nVNS was examined in 10 studies for the treatment of primary headache: four studies of the acute treatment of migraine, four studies in migraine prevention, two studies in acute cluster headache treatment and one study in cluster headache prevention. One nVNS study included acute and preventive migraine treatment regimens and was assessed in both interventions. Four studies were registered on ClinicalTrials.gov or another WHO primary registry but were not yet published, whereas six studies were both published and registered.

\section{Migraine}

In the acute treatment of migraine (table 2), the four nVNS studies had a total population of 396 patients who had migraine with and without aura. Two of the acute nVNS trials used blinding and sham controls along with the IHS-recommended primary and secondary efficacy endpoints; the remaining two acute nVNS trials were exclusively safety studies and were not included in the assessment of efficacy endpoints. One nVNS study (ClinicalTrials.gov identifier: NCT02378844) evaluated both acute and preventive treatment regimens and included patients with either episodic or chronic migraine; the IHS recommends excluding patients with chronic migraine from acute treatment studies, but the primary and secondary endpoints of this study were focused on evaluating migraine prevention. ${ }^{20}$ In migraine prevention (table 3 ), the four nVNS studies had a total population of 626 patients who had migraine with and without aura. Three of the preventive nVNS trials used blinding and sham controls along with at least one of the IHS-recommended primary efficacy endpoints; one trial used the pertinent IHS-recommended secondary efficacy endpoints. One preventive nVNS trial was designed as a safety study and was not included in the assessment of efficacy endpoints.

Table 4 Non-invasive neuromodulation clinical trials in acute and preventive cluster headache treatments

\begin{tabular}{|c|c|c|c|c|c|c|}
\hline \multirow[b]{2}{*}{ Device type* } & \multirow[b]{2}{*}{ Studies (n) } & \multirow{2}{*}{$\begin{array}{l}\text { Enrolled } \\
\text { population } \\
\text { (total } n \text { ) }\end{array}$} & \multirow[b]{2}{*}{$\begin{array}{l}\text { Blinded studies } \\
\text { (n) } \dagger\end{array}$} & \multirow[b]{2}{*}{$\begin{array}{l}\text { Sham-controlled } \\
\text { studies (n) }\end{array}$} & \multicolumn{2}{|c|}{$\begin{array}{l}\text { Percentage of studies evaluating IHS- } \\
\text { recommended endpoints }\end{array}$} \\
\hline & & & & & $\begin{array}{l}\text { Primary endpoint } \\
(\%) \ddagger\end{array}$ & $\begin{array}{l}\text { Secondary endpoint } \\
(\%) \ddagger\end{array}$ \\
\hline \multicolumn{7}{|l|}{ Acute cluster headache treatments } \\
\hline Non-invasive vagus nerve stimulation (nVNS) & 2 & 253 & 2 & 2 & 100 & 100 \\
\hline \multicolumn{7}{|l|}{ Preventive cluster headache treatments } \\
\hline Non-invasive vagus nerve stimulation (nVNS) & $1 \S$ & 97 & 0 & 0 & 100 & 100 \\
\hline Transcranial direct current stimulation (tDCS) & 1 & 32 & 0 & 0 & 0 & 100 \\
\hline $\begin{array}{l}\text { *All references for studies in this table are listed } \\
\text { †Double-blind or better. } \\
\text { †Percentage of efficacy studies in which either a } \\
\text { from this calculation. } \\
\text { §Marin et al's study (used for recent Food and D } \\
\text { IHS, International Headache Society. }\end{array}$ & imary or a se & $\begin{array}{l}\text { lary endpoint } \\
\text { learance) no }\end{array}$ & $\begin{array}{l}\text { nended by the Inte } \\
\text { d here as it was } p\end{array}$ & $\begin{array}{l}\text { ernational Headach } \\
\text { ublished outside o }\end{array}$ & $\begin{array}{l}\text { ociety was used. Saf } \\
\text { edefined date range. }\end{array}$ & tudies were excluded \\
\hline
\end{tabular}

Reuter U, et al. J Neurol Neurosurg Psychiatry 2019;90:796-804. doi:10.1136/jnnp-2018-320113 
Cluster headache

nVNS is the only identified non-invasive neuromodulation device that has been evaluated in the acute treatment of cluster headache (table 4). The two nVNS studies had a total population of 253 patients, were blinded and sham controlled and adhered to the IHS-recommended primary and secondary efficacy endpoints. In cluster headache prevention (table 4), one study with a population sample size of 97 patients was randomised and controlled, but not blinded or sham controlled. This study adhered to the IHS-recommended primary and secondary efficacy endpoints.

\section{External trigeminal nerve stimulation \\ Migraine}

e-TNS was examined in six studies for the acute or preventive treatment of migraine. Four studies were registered on ClinicalTrials.gov, one study was published and registered and one study was published without registration.

In the acute treatment of migraine (table 2), the three e-TNS studies had a total population of 196 patients with and without aura; one study was blinded and sham controlled. One acute e-TNS study used a primary endpoint recommended by the IHS. All three studies used at least one IHS-recommended secondary efficacy endpoint. Contrary to IHS recommendations for studies in acute migraine treatment, two of these studies included patients with chronic migraine. In preventive migraine (table 3), the three e-TNS studies had a total population of 194 patients with and without aura; one study was blinded and sham controlled. One preventive e-TNS study used a primary efficacy endpoint recommended by the IHS; all three studies used at least one IHS-recommended secondary efficacy endpoint.

\section{Cluster headache}

No e-TNS studies for the treatment of cluster headache were identified.

\section{Single-pulse transcranial magnetic stimulation Migraine}

sTMS was evaluated in three studies for the acute and preventive treatment of migraine. Two studies were published and registered; one study was published without registration.

In the acute treatment of migraine (table 2), the two sTMS studies had a total population of 309 patients. One study used patients with and without aura. Both acute studies were blinded, and one used a sham control. One acute sTMS study used the IHS-recommended primary and secondary efficacy endpoints. One sTMS study in the acute treatment of migraine did not adhere to the IHS recommendation of excluding patients with chronic migraine. The preventive sTMS study evaluated 263 patients (table 3) with either episodic or chronic migraine, both with or without aura. The study was not blinded or sham controlled. A reduction in headache days rather than the IHS-recommended reduction in migraine days was used as the primary efficacy endpoint. Three IHS-recommended secondary efficacy endpoints for the prevention of either episodic or chronic migraine were used.

\section{Cluster headache}

No sTMS studies for the treatment of cluster headache were identified.

\section{Repetitive transcranial magnetic stimulation}

Migraine

rTMS was evaluated in 11 studies for the acute and preventive treatment of migraine. Four studies were registered on ClinicalTrials.gov or another WHO primary registry but were not published; one study was published and registered; six studies were published without registration.

In the acute treatment of migraine (table 2), one rTMS study of 201 patients was identified. The rTMS study was blinded and sham controlled and included only patients with aura. The rTMS study used IHS-recommended primary and secondary efficacy endpoints. In migraine prevention (table 3), 10 rTMS studies with a total population of 416 patients were identified. Nine studies on rTMS for preventive treatment evaluated patients with migraine with and without aura, five studies were blinded and eight studies were sham controlled. Thirty per cent of the preventive rTMS studies used IHS-recommended primary efficacy endpoints, and 80\% used IHS-recommended secondary efficacy endpoints.

\section{Cluster headache}

No studies of the rTMS device for the treatment of cluster headache were identified.

\section{Transcranial direct current stimulation}

tDCS was evaluated in 20 studies for the acute and preventive treatment of migraine and for chronic cluster headache prevention. Fifteen studies were registered on ClinicalTrials.gov or another WHO primary registry but were not published; one study was published and registered; four studies were published without registration.

\section{Migraine}

In the acute treatment of migraine (table 2), the single tDCS study had a population of 32 patients with and without aura; the study was neither blinded nor sham controlled and did not evaluate IHS-recommended primary and secondary endpoints. In migraine prevention (table 3), 18 studies were evaluated with a total population of 855 patients. Seventeen studies had patients with and without aura, 15 studies were blinded and 15 studies were sham controlled. Fifty per cent of the studies used an IHS-recommended primary efficacy endpoint, and $72 \%$ used an IHS-recommended secondary efficacy endpoint.

\section{Cluster headache}

In cluster headache prevention (table 4), one tDCS study was identified. The study included 32 patients and was not blinded or sham controlled. An IHS-recommended primary efficacy endpoint was not used, but three IHS-recommended secondary efficacy endpoints were used.

\section{Occipital and supraorbital transcutaneous nerve stimulation Migraine}

OS-TNS was evaluated in three studies of the acute treatment of migraine (table 2), which were registered on ClinicalTrials.gov but not published. These studies had a total population of 106 patients who had migraine with and without aura. All were sham controlled, but only two of the three were blinded. None of the OS-TNS studies used the IHS-recommended primary endpoint, but all used at least one IHS-recommended secondary endpoint. Two of the acute studies did not comply with the IHS recommendation to exclude patients with chronic migraine. 
Cluster headache

No studies of the OS-TNS device for the treatment of cluster headache were identified.

\section{Conditioned pain modulation \\ Migraine}

CPM was evaluated in three studies of the acute treatment of migraine (table 2): two studies were only registered on ClinicalTrials.gov, and one study was both published and registered. The three CPM studies had a total population of 476 patients, and all three consisted of patients with migraine with and without aura and were blinded and sham controlled. None of the CPM studies used the IHS-recommended primary endpoint, and only one used at least one of the IHS-recommended secondary endpoints.

\section{Cluster headache}

No studies of the CPM device for the treatment of cluster headache were identified.

\section{Caloric vestibular stimulation}

Migraine

CVS was evaluated in three studies of migraine prevention (table 3); two studies were registered on ClinicalTrials.gov but not published; one study was both published and registered. The three CVS studies had a total population of 291 patients; two studies enrolled patients with migraine with and without aura. Two studies were blinded and sham controlled. All three studies used at least one of the IHS-recommended primary efficacy endpoints; two of the CVS studies used at least one of the IHS-recommended secondary efficacy endpoints.

\section{Cluster headache}

No studies of the CVS device for the treatment of cluster headache were identified.

\section{DISCUSSION}

We conducted a comprehensive systematic review of non-invasive neuromodulation clinical trials in migraine and cluster headache using the PRISMA criteria to ensure an unbiased analysis of all relevant studies. This analysis used the current IHS recommendations for drug studies as a benchmark for scientific rigour in the absence of guidelines specific to non-invasive neuromodulation $^{16-18}$ and further demonstrated the heterogeneity of study designs and endpoints in clinical trials with non-invasive neuromodulation. The IHS guidelines for acute treatment studies of migraine recommend the assessment of migraine pain at a consistent time point (ie, pain freedom at 2 hours) after the intervention, and guidelines for studies of preventive migraine treatments recommend one of three clinically relevant outcomes (ie, change in migraine days, change in moderate to severe headache days, or responder rate), with the remaining two recommended as secondary endpoints.

In our systematic search, we identified pivotal studies for the three non-invasive neuromodulation therapies with regulatory clearance for migraine and/or cluster headache (ie, nVNS, e-TNS, sTMS), which are the focus of this discussion. Pivotal studies are clinical trials intended to provide evidence for regulatory approval. Publications of these studies for the available devices were assessed using the criteria provided by the European Federation of Neurological Societies (EFNS; table 5). ${ }^{21-30}$ Studies with a published classification of evidence by the American Academy of Neurology were also assessed alongside the EFNS criteria. ${ }^{21273132}$ Two of the pivotal studies in the acute treatment of migraine, Tassorelli et al's ${ }^{21}$ study of nVNS $(\mathrm{n}=285)$ and Lipton et al's ${ }^{28}$ study of sTMS $(n=267)$, had comparable population sample sizes, with the e-TNS pivotal trial having enrolled a smaller number of patients $(n=106) .{ }^{26}$ Of all identified clinical studies of migraine prevention, the PREMIUM study of nVNS had the largest population sample $(n=479) .^{20} 33$ The pivotal trials by Starling et $a l^{29}$ for sTMS and by Schoenen et $a l^{27}$ for e-TNS used population sample sizes of 263 and 84 patients, respectively. The nVNS and e-TNS pivotal trials in the acute treatment of migraine and all three key migraine prevention studies followed the IHS recommendation to enrol patients both with and without aura, whereas the acute sTMS study evaluated only patients with aura. All three pivotal studies of the acute treatment of migraine as well as the PREMIUM preventive nVNS trial and the pivotal study of preventive e-TNS were blinded and sham controlled. The pivotal study of sTMS in migraine prevention was an open-label trial and used an estimate of the placebo effect that was statistically derived according to historical controls (ie, performance goal) rather than a sham control group.

The pivotal studies of acute nVNS and sTMS evaluated the IHS-recommended primary endpoint of pain freedom at 2 hours. The acute e-TNS pivotal study predefined its primary endpoint as the change in visual analogue scale pain score at 1 hour and used pain freedom at 2 hours as a secondary endpoint. Therapeutic effects on the pain-free response rate at 2 hours were comparable among the three pivotal studies of acute treatment, with significance (vs sham) demonstrated for sTMS (active, $39 \%$; sham, 22\%; $\mathrm{p}=0.0179)^{28}$ but not for nVNS (active, $30.4 \%$; sham, $19.7 \%$; $\mathrm{p}=0.067)^{21}$ or e-TNS (active, $19 \%$; sham, $8 \% ; \mathrm{p}=0.136) .{ }^{26}$ The IHS-recommended primary endpoint of the reduction in migraine days (from run-in to the third month of therapy) was used in the key migraine prevention trials for both $\mathrm{nVNS}$ (active, -2.26 days; sham, -1.80 days; $\mathrm{p}=0.146$ ) and e-TNS (active, -2.06 days; sham, -0.32 days; $p=0.054$ ), ${ }^{27}$ whereas the pivotal preventive sTMS study used the reduction in headache days as the primary endpoint and did not evaluate the reduction in migraine-specific pain. ${ }^{29}$

Interpretation of the acute and preventive findings across the three devices is challenging because of differences in patient characteristics, rescue medication use and sham devices used in the trials. The acute sTMS study results represent those of an aura population, whereas the acute nVNS and e-TNS results are from a population composed of patients both with and without aura. The acute e-TNS study allowed rescue medication use within 24 hours after treatment, whereas the acute nVNS and sTMS studies defined requirements to delay rescue medication use for 2 hours. $^{212628}$ The therapeutic difference between nVNS and sham in both the acute and preventive nVNS studies was likely affected by the elevated effects in the sham groups. The sham device that was used in the nVNS trials was shown in a separate study to be partially active according to its observed inhibitory effects on the trigeminal autonomic reflex. ${ }^{34}$ This heterogeneity in the pivotal studies of nVNS, e-TNS and sTMS makes the comparison of these devices and their efficacy outcomes difficult.

The nVNS device is the only non-invasive neuromodulation therapy currently cleared for acute and preventive use in cluster headache. Only one other device (ie, tDCS for preventive use) has been evaluated in a study of cluster headache. The two pivotal studies of nVNS for acute cluster headache treatment (ACT1 and ACT2) evaluated primary endpoints consistent with IHS recommendations: pain relief at $15 \mathrm{~min}$ for the first attack without rescue medication use through $60 \mathrm{~min}$ and pain freedom at 15 


\begin{tabular}{|c|c|c|c|c|c|c|}
\hline Device & Study & Authors & CE marked & FDA cleared & $\begin{array}{l}\text { AAN Classification } \\
\text { of Evidence }\end{array}$ & GRADE \\
\hline \multirow[t]{6}{*}{ nVNS } & $\begin{array}{l}\text { Acute migraine } \\
\text { treatment }{ }^{*}\end{array}$ & Tassorelli et al ${ }^{21}$ & Yes & Yes & 1 & High \\
\hline & $\begin{array}{l}\text { Migraine } \\
\text { prevention* } \dagger\end{array}$ & $\begin{array}{l}\text { Silberstein et al } \\
(\text { EVENT) })^{31}\end{array}$ & Yes & No & $\|$ & Low \\
\hline & $\begin{array}{l}\text { Acute } \mathrm{CH} \\
\text { treatment }\end{array}$ & $\begin{array}{l}\text { Silberstein et al } \\
(\mathrm{ACT} 1)^{22}\end{array}$ & Yes & Yes" & NA & High \\
\hline & & Goadsby et $a^{23}$ & & & NA & High \\
\hline & CH prevention $\ddagger$ & Gaul et $a l^{24}$ & Yes & Yes & NA & High \\
\hline & & Marin et $a l^{25}$ & & & NA & Moderate \\
\hline \multirow[t]{4}{*}{ e-TNS } & $\begin{array}{l}\text { Acute migraine } \\
\text { treatment }\end{array}$ & Chou et a ${ }^{26}$ & Yes & Yes & NA & Moderate \\
\hline & $\begin{array}{l}\text { Migraine } \\
\text { prevention* }\end{array}$ & Schoenen et $a l^{27}$ & Yes & Yes & III & Moderate \\
\hline & $\begin{array}{l}\text { Acute } \mathrm{CH} \\
\text { treatment§ }\end{array}$ & NA & No & No & NA & NA \\
\hline & CH prevention§ & NA & No & No & NA & NA \\
\hline \multirow[t]{4}{*}{ sTMS } & $\begin{array}{l}\text { Acute migraine } \\
\text { treatment }\end{array}$ & Lipton et $a l^{28}$ & Yes & Yes & NA & Moderate \\
\hline & $\begin{array}{l}\text { Migraine } \\
\text { prevention }\end{array}$ & Starling et $\left.a\right|^{29}$ & Yes & Yes & NA & Low \\
\hline & $\begin{array}{l}\text { Acute } \mathrm{CH} \\
\text { treatment§ }\end{array}$ & NA & No & No & NA & NA \\
\hline & $\mathrm{CH}$ prevention§ & NA & No & No & NA & NA \\
\hline
\end{tabular}

${ }^{*}$ AAN Classification of Evidence is published for this study.

tThe EVENT study was not a pivotal study.

¥Marin et al's study published outside of predefined date range; included here based on recent FDA clearance.

$\S$ No studies identified.

9FDA cleared for episodic CH only.

AAN, American Academy of Neurology; ACT, acute CH treatment; $\mathrm{CH}$, cluster headache; FDA, Food and Drug Administration; GRADE, Grading of Recommendations Assessment, Development and Evaluation; NA, not available; e-TNS, external trigeminal nerve stimulation; nVNS, non-invasive vagus nerve stimulation; sTMS, single-pulse transcranial magnetic stimulation.

min among all attacks without rescue medication use through 15 min. ${ }^{22} 23$ Significant therapeutic benefits were observed for the episodic cluster headache cohorts of both ACT1 (active, 34.2\%; sham, $10.6 \% ; \mathrm{p}=0.008$ ) 22 and ACT2 (active, 48.0\%; sham, $6.0 \% ; \mathrm{p}<0.01)^{23}$ but not for the total populations or chronic cluster headache cohorts. The two pivotal studies of nVNS for preventive use in cluster headache evaluated the frequency of attacks per week as the primary endpoint ${ }^{24}{ }^{25}$ which is consistent with IHS recommendations. ${ }^{18}$ The PREVA ${ }^{24}$ study indicated a significantly greater reduction in the number of attacks per week versus controls ( -5.9 vs -2.1 , respectively) for a mean therapeutic gain of 3.9 fewer attacks per week $(p=0.02)$. Marin et al' $\mathrm{s}^{25}$ study demonstrated a decrease in mean attack frequency from 26.6 attacks per week before initiation of nVNS treatment to 9.5 attacks per week $(\mathrm{p}<0.01)$ afterward.

The scope of this systematic review was limited by the heterogeneity among the clinical trials analysed and the unavailability of many of the study results, which precluded a formal systematic meta-analysis of all identified studies. Thirty-seven of the 41 studies that were registered with ClinicalTrials.gov or another registry but not published did not have results available, and some did not comprehensively report all study design components examined. Studies evaluated in this review are heterogeneous in both study design and statistical power (ie, patient population sample size), which affects the ability to interpret and compare the true effects. ${ }^{35}{ }^{36}$ Uniform use of prespecified outcome measures and other study design components is essential for conducting meta-analyses and cost-benefit analyses to compare different treatment interventions. It was not the scope of this review to compare the results of these clinical trials as they are heterogeneous.

The results of this review suggest several considerations for the ongoing development of clinical trial guidelines for non-invasive neuromodulation devices in primary headache. First, in an acute setting, the IHS emphasis on the first attack may not be optimal for non-invasive neuromodulation devices. These devices require patient training to ensure proper administration, which may not be complete at the first attack. To allow for complete patient training with non-invasive neuromodulation devices, it may be advisable to assess the efficacy of multiple attacks or after proper administration is demonstrated. Second, the mechanisms of preventive neuromodulation (eg, electrical or magnetic) treatments in primary headache are indirect, and efficacy may be multidimensional when considering the different pathophysiologies of migraine and cluster headache. The full preventive potential of a neuromodulation regimen may be best captured with an observational time period equal to that of the IHS-recommended period for pharmacological therapies (ie, a minimum 12 weeks). Third, reproducibility is needed to support the validity of efficacy outcomes in all therapeutic trials. Many neuromodulation devices have not yet been evaluated in multiple randomised controlled studies. The field of neuromodulation would benefit if more devices were evaluated in more than one rigorous study to support efficacy outcomes. Lastly, appropriate blinding is a particular challenge in non-invasive neuromodulation trials. Ideally, the sham device should mimic the active device as closely as possible while avoiding any inadvertent nerve activity. Sham devices with an active signal risk producing 
an active therapeutic effect, which could diminish the ability to achieve significant treatment differences. The suggested modifications to clinical design elements recommended in this review could support scientific rigour and inform the development of recommendations for non-invasive neuromodulation studies in migraine and cluster headache.

The efficacy and low side effect burden of non-invasive neuromodulation make it a practical, tolerable and safe therapeutic option for patients and clinicians, but efficacy may vary across the different devices. Greater rigour and consistency among non-invasive neuromodulation studies are needed to improve clinicians' ability to select the appropriate option for their patients. Development of guidelines for evaluating the efficacy of non-invasive neuromodulation therapies is under way. Well-designed studies, such as those for nVNS that consistently adhere to stringent IHS recommendations for pharmacological trials, may help in the design of future clinical trials until neuromodulation-specific guidelines are established.

\section{CONCLUSIONS}

In this systematic review of non-invasive neuromodulation device studies in the acute and preventive treatment of migraine and cluster headache, nVNS studies demonstrated the most consistent adherence to IHS recommendations. Future trials should be rigorously designed to facilitate comparisons across devices. Guidelines specific to evaluating non-invasive neuromodulation therapies for the treatment of migraine and cluster headache will soon be available, but adherence to current recommendations for pharmacological trials will minimise heterogeneity among neuromodulation studies.

\section{Acknowledgements Technical and editorial support for this manuscript was provided by Mark Skopin, PhD, Stefanie Dorlas, BMath, BEd, and Martin Kurtev, MS, of MedLogix Communications.}

Contributors UR, EL and PP-R provided detailed input into the development of the manuscript. UR conceptualised the manuscript. All authors participated in data collection, interpretation, and validation and had full access to all data in the manuscript. All authors reviewed, critiqued and contributed to revision of the manuscript content and provided approval of the final manuscript draft. Professional medical writing, data and editorial support (ie, technical editing, copyediting, preparation of tables and figures and clerical assistance) from MedLogix Communications was funded by electroCore. The principal author, UR, takes responsibility for the data, analyses and interpretation, and conduct of the research.

Funding This review was sponsored by electroCore. An employee of the sponsor was involved in data collection, interpretation and validation. All authors, including an employee of the study sponsor, drafted and/or revised the manuscript and approved the final version for submission. Professional medical writing, data and editorial support (ie, technical editing, copyediting, preparation of tables and figures and clerical assistance) from MedLogix Communications was funded by electroCore.

Competing interests PP-R has received honoraria as a consultant and speaker for Allergan, Amgen, Almirall, Chiesi, Eli Lilly, Janssen Cilag, Medscape, MSD, Novartis, and Teva. Her research group has received research grants from Allergan and has received funding for clinical trials from Alder, Boehringer Ingelheim, MSD, electroCore, Eli Lilly, Janssen Cilag, Novartis, and Teva. She is a trustee member of the board of the International Headache Society, a member of the Council of the European Headache Federation, and coordinator of the Spanish Headache Study Group of the Spanish Neurological Society. She is on the editorial board of Revista de Neurologia. She is an editor for Frontiers in Neurology and The Journal of Headache and Pain. She is a member of the Clinical Trials Guidelines Committee of the International Headache Society. She has edited the Guidelines for the Diagnosis and Treatment of Headache of the Spanish Neurological Society. She is the founder of www.midolordecabeza.org. She does not own stocks in any pharmaceutical company. CM is an employee of North American Science Associates, Inc. EL is an employee of electroCore, Inc., and receives stock ownership. UR has received honoraria as a consultant and speaker for Allergan, Amgen, Autonomic Technologies, Eli Lilly, electroCore, Novartis, Medscape, StreMedup, and Teva. He has participated in clinical trials from Allergan, Alder, Amgen, Autonomic Technologies, Eli Lilly, electroCore, Novartis, and Teva. He is a board member of the European Headache
Federation. He is on the editorial boards of The Journal of Headache and Pain and Frontiers in Neurology.

Patient consent for publication Not required.

Provenance and peer review Not commissioned; externally peer reviewed.

Open access This is an open access article distributed in accordance with the Creative Commons Attribution Non Commercial (CC BY-NC 4.0) license, which permits others to distribute, remix, adapt, build upon this work non-commercially, and license their derivative works on different terms, provided the original work is properly cited, appropriate credit is given, any changes made indicated, and the use is non-commercial. See: http://creativecommons.org/licenses/by-nc/4.0/.

\section{REFERENCES}

1 Martel MO, Finan PH, Dolman AJ, et al. Self-reports of medication side effects and pain-related activity interference in patients with chronic pain. PAIN 2015;156:1-1100.

2 Schwedt TJ, Vargas B. Neurostimulation for treatment of migraine and cluster headache. Pain Med 2015;16:1827-34.

3 Martelletti P, Jensen RH, Antal A, et al. Neuromodulation of chronic headaches: position statement from the European headache Federation. J Headache Pain 2013;14.

4 electroCore, Inc. gammaCore ${ }^{-S}$ S [Instructions for Use. Basking Ridge, NJ: electroCore, Inc., 2018.

5 Cefaly US Inc. Cefaly dual. Available: https://www.cefaly.us/. Updated 2018 [Accessed 16 Nov 2018].

6 eNeura Inc. sTMS miniTM [Instructions for Use]. Sunnyvale, CA: eNeura Inc., 2018

7 Hougaard A, Tfelt-Hansen P. Are the current IHS guidelines for migraine drug trials being followed? J Headache Pain 2010;11:457-68

8 Moher D, Liberati A, Tetzlaff J, et al. Preferred reporting items for systematic reviews and meta-analyses: the PRISMA statement. BMJ 2009;339:b2535.

9 Clinical trials registration and results information submission. Available: https://www. federalregister.gov/documents/2016/09/21/2016-22129/clinical-trials-registrationand-results-information-submission [Accessed 15 Aug 2018].

10 Section 801 of the food and drug administration amendments act of 2007. Available: https://www.gpo.gov/fdsys/pkg/PLAW-110publ85/pdf/PLAW-110publ85.pdf\#page= 82 [Accessed 15 Aug 2018].

11 International Committee of Medical Journal Editors. Clinical trials. Available: http:// www.icmje.org/recommendations/browse/publishing-and-editorial-issues/clinical-trialregistration.html. Identifier. [Accessed 15 Aug 2018].

12 Bashir R, Bourgeois FT, Dunn AG. A systematic review of the processes used to link clinical trial registrations to their published results. Syst Rev 2017;6.

13 Classification and diagnostic criteria for headache disorders, cranial neuralgias and facial pain. Headache classification Committee of the International Headache Society. Cephalalgia 1988;8(suppl 7):1-96.

14 Headache Classification Subcommittee of the International Headache Society. The International Classification of Headache Disorders: 2nd edition. Cephalalgia 2004;24 suppl 1:9-160.

15 Headache Classification Committee of the International Headache Society. The International Classification of Headache Disorders: 3rd edition. Cephalalgia 2018;38:1-211.

16 Tfelt-Hansen P, Pascual J, Ramadan N, et al. Guidelines for controlled trials of drugs in migraine: third edition. A guide for Investigators. Cephalalgia 2012;32:6-38.

17 Tassorelli C, Diener H-C, Dodick DW, et al. Guidelines of the International Headache Society for controlled trials of preventive treatment of chronic migraine in adults. Cephalalgia 2018:38:815-32.

18 Lipton RB, Micieli G, Russell D, et al. Guidelines for controlled trials of drugs in cluster headache. Cephalalgia 1995;15:452-62.

19 World Health Organization, 2015. WHO statement on public disclosure of clinical trial results. Available: http://www.who.int/ictrp/results/WHO_Statement_results reporting_clinical_trials.pdf?ua=1. Updated April 9 [Accessed 16 Aug 2018].

20 ClinicalTrials.gov. A randomized, sham-controlled study of gammaCore $®$ (nVNS) for prevention of episodic migraine. Available: https://clinicaltrials.gov/ct2/show/ NCT02378844 [Accessed 2 Apr 2018].

21 Tassorelli C, Grazzi L, de Tommaso M, et al. Noninvasive vagus nerve stimulation as acute therapy for migraine: The randomized PRESTO study. Neurology 2018;91:e364-73.

22 Silberstein SD, Mechtler LL, Kudrow DB, et al. Non-Invasive Vagus Nerve Stimulation for the ACute Treatment of Cluster Headache: Findings From the Randomized, DoubleBlind, Sham-Controlled ACT1 Study. Headache: The Journal of Head and Face Pain 2016:56:1317-32.

23 Goadsby PJ, de Coo IF, Silver N, et al. Non-invasive vagus nerve stimulation for the acute treatment of episodic and chronic cluster headache: a randomized, doubleblind, sham-controlled ACT2 study. Cephalalgia 2018;38:959-69.

24 Gaul C, Diener HC, Silver N, et al. Non-invasive vagus nerve stimulation for prevention and acute treatment of chronic cluster headache (PREVA): a randomised controlled study. Cephalalgia 2016;36:534-46. 
25 Marin J, Giffin N, Consiglio E, et al. Non-invasive vagus nerve stimulation for treatment of cluster headache: early UK clinical experience. J Headache Pain 2018;19.

26 Chou DE, Shnayderman Yugrakh M, Winegarner D, et al. Acute migraine therapy with external trigeminal neurostimulation (ACME): a randomized controlled trial. Cephalalgia 2018.

27 Schoenen J, Vandersmissen B, Jeangette S, et al. Migraine prevention with a supraorbital transcutaneous stimulator: a randomized controlled trial. Neurology 2013;80:697-704.

28 Lipton RB, Dodick DW, Silberstein SD, et al. Single-pulse transcranial magnetic stimulation for acute treatment of migraine with aura: a randomised, double-blind, parallel-group, sham-controlled trial. Lancet Neurol 2010;9:373-80.

29 Starling AJ, Tepper SJ, Marmura MJ, et al. A multicenter, prospective, single Arm, open label, observational study of sTMS for migraine prevention (ESPOUSE study). Cephalalgia 2018;38:1038-48.

30 Leone MA, Brainin M, Boon P, et al. Guidance for the preparation of neurological management guidelines by EFNS scientific task forces - revised recommendations 2012. Eur J Neurol 2013;20:410-9.
31 Silberstein SD, Calhoun AH, Lipton RB, et al. Chronic migraine headache prevention with noninvasive vagus nerve stimulation. Neurology 2016;87:529-38.

32 Gronseth GS, Cox J, Gloss D, et al. Classification of evidence schemes: criteria for rating theurapeutic studies. In: American academy of neurology clinical practice guideline process manual. 2017. American Academy of Neurology: Guideline Development, Dissemination, and Implementation Subcommittee, 2017

33 Diener HC, Goadsby PJ, Ashina M, et al. Non-invasive vagus nerve stimulation (nVNS) for the preventive treatment of episodic migraine: the multicentre, double-blind, randomised, sham-controlled premium trial. Paper presented at: Migraine Trust International Symposium, London, United Kingdom, 2018

34 Moeller M, Schroeder C, May A. Comparison of active and "sham" non-invasive vagal nerve stimulation on lacrimation in healthy volunteers. San Francisco, CA: American Headache Society, 2018.

35 Nord CL, Valton V, Wood J, et al. Power-up: a reanalysis of 'power failure' in neuroscience using mixture modeling. J Neurosci 2017;37:8051-61.

36 Button KS, loannidis JPA, Mokrysz C, et al. Power failure: why small sample size undermines the reliability of neuroscience. Nat Rev Neurosci 2013;14:365-76. 